\title{
内頸動脈閉塞を伴う巨大脳底動脈先端部近傍動脈瘤の外科治療
}

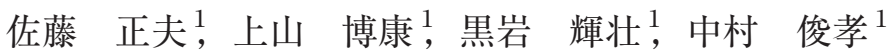 \\ 瀧澤 克己 ${ }^{1}$, 浅岡 克行 ${ }^{1}$, 原田 洋一 ${ }^{1}$, 山下 圭一 $^{1}$ \\ 航晃仁 ${ }^{1}$, 杉山 拓, 谷川 緑野 ${ }^{2}$
}

\section{Surgical Treatment of Giant Basilar Tip Aneurysms with Unilateral Internal Carotid Artery Occlusion}

\author{
Masao Sato, M.D., ${ }^{1}$ Hiroyasu Kamiyama, M.D., ${ }^{1}$ Terumasa Kuroiwa, M.D., ${ }^{1}$ \\ Toshitaka Nakamura, M.D., ${ }^{1}$ Katsumi Takizawa, M.D., ${ }^{1}$ Katsuyuki AsaOKA, M.D., ${ }^{1}$ \\ Yoichi Harada, M.D., ${ }^{1}$ Keiichi Yamashita, M.D., ${ }^{1}$ Akihito KoH, M.D., ${ }^{1}$ \\ Taku Sugiyama, M.D., ${ }^{1}$ and Rokuya Tanikawa, M.D. ${ }^{2}$ \\ ${ }^{1}$ Department of Neurosurgery, Asahikawa Red Cross Hospital, Asahikawa, and ${ }^{2}$ Abashiri \\ Neurosurgical-Rehabilitation Hospital, Abashiri, Japan
}

Summary: We report 4 cases of giant aneurysms in the basilar tip region, comprising 1 large and 3 giant aneurysms located in the basilar tip (2 cases), basilar-SCA ( 1 case), and PCA (1 case). One of the 4 was ruptured (basilar tip aneurysm). The symptoms were headache ( 3 cases) and oculomotor palsy (1 case; basilar-SCA). All aneurysms had unilateral internal carotid artery occlusion. In all cases the aneurysms were clipped following EC-RA-M2 bypass to prevent ischemia at the area of the occluded internal carotid artery and to reduce hemodynamic stress within the aneurysm. The clinical courses of 2 basilar tip aneurysms were good but 1 basilar-SCA aneurysm re-grew and ruptured 4 years later after incomplete clipping of the aneurysm. In 1 PCA aneurysm a new basilar tip aneurysm occurred that grew progressively. We consider that the cause of these aneurysms was hemodynamic stress due to internal carotid artery occlusion. It is suggested that the internal carotid artery should not be occluded without an EC-RA-M2 bypass.

\author{
Key words: \\ - basilar tip \\ - internal carotid artery \\ occlusion \\ - hemodynamic \\ - aneurysm \\ - EC-RA-M2 bypass
}

Surg Cereb Stroke (Jpn) 36: 265-270, 2008

\section{はじめに}

一側あるいは両側内頸動脈閉塞に脳動脈瘤を併発するこ とが知られている ${ }^{3) 4010)}$ が，このような動脈瘤の治療は動 脈瘤のみを処置する場合が多い. 右内頸動脈閉塞を伴う破 裂前交通動脈瘤に対し, 動脈瘤をクリッピング後 STA$\mathrm{MCA}$ バイパスを行った報告 ${ }^{10)}$ はあるが， high flow bypass を行ってから動脈瘤の治療を行っている症例 (くも 膜下出血にて発症，左内頸動脈閉塞を伴う脳底動脈先端部 動脈瘤) は谷川ら ${ }^{14)}$ が報告しているにすぎない。一方，内 頸動脈閉塞に伴う動脈痕は hemodynamic stress が動脈瘤 の発生・形成に深く関与していることがあり，動脈瘤が生 じる部位は前方循環および脳底動脈周囲に多いとされてい $ろ^{4)}$. 脳底動脈遠位部に動脈瘤が生じた場合，母動脈の遮

${ }^{1}$ 旭川赤十字病院 脳神経外科, ${ }^{2}$ 網走脳神経外科リハビリテーション病院(受稿日 2007.9.5) (脱稿日 2007. 12. 25)〔連絡先：テ078-8510 北海道旭川市緑が丘東 2 条 1 丁目 旭川医科大学 脳神経外科 佐藤正夫] [Address correspondence: Masao SATO, M.D., Asahikawa Medical College, 1-chome, Higashi 2-jo, Midorigaoka, Asahikawa, Hokkaido 078-8510, Japan] 


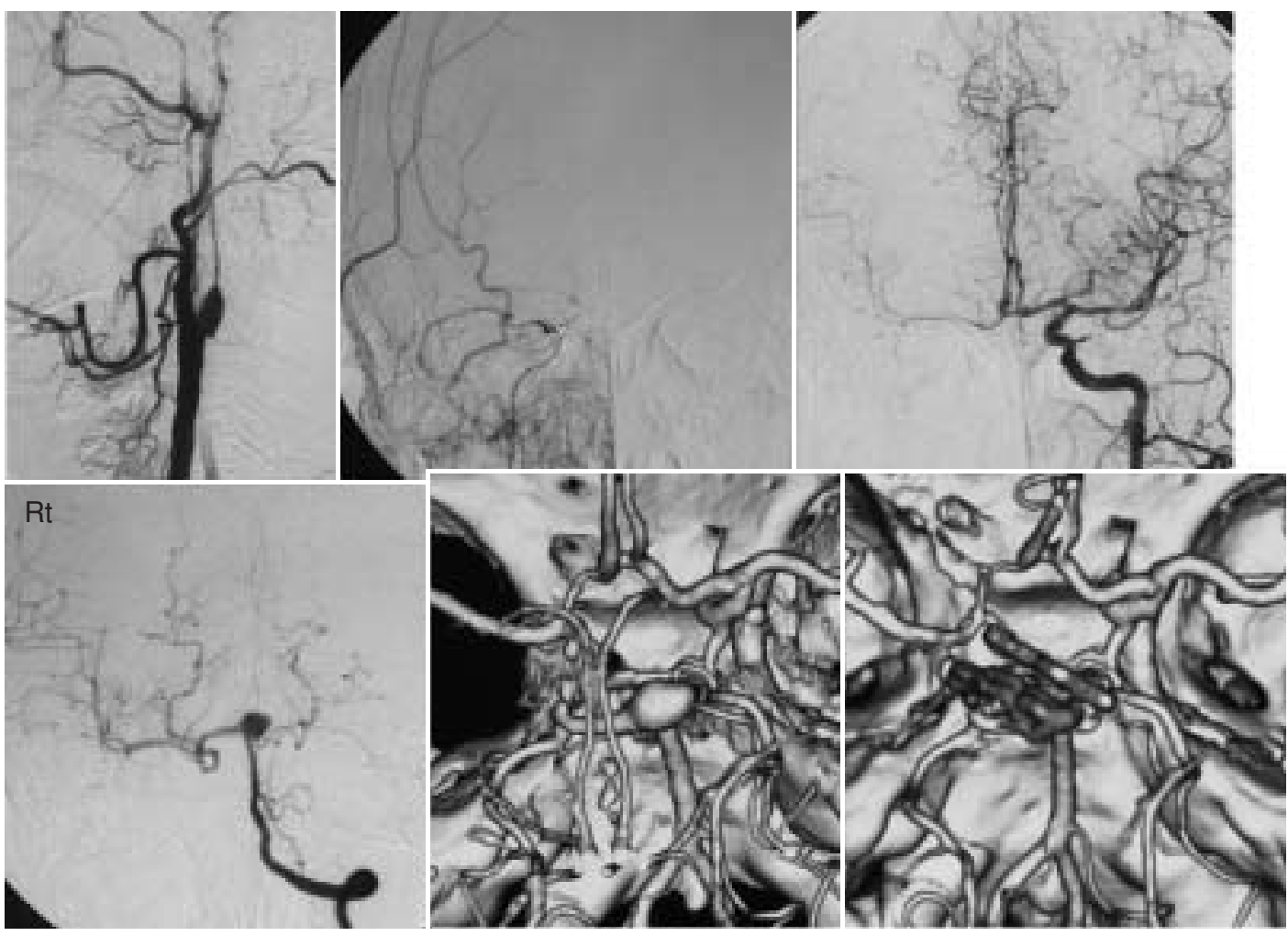

Fig. 1 Case 1. Angiograms show it. internal carotid artery occlusion and a basilar tip aneurysm: rt. CAG lateral view (A), rt. CAG A-P view (B), It. CAG A-P view $(C)$, It. VAG A-P view (D). 3D-CTA reveals a basilar tip aneurysm in before (E) and after clipping (F).

\begin{tabular}{l|l|l} 
A & B & C \\
\hline$D$ & E & F
\end{tabular}

断が難しくなり，動脈瘤が大きいと治療そのものが困難と なる場合も少なくない，今回われわれは，一側内頸動脈閉 塞を伴い脳底動脈およびその近傍に生じた巨大動脈藘を経 験したので報告する.

\section{症例}

〈症例 1〉69歳女性. 頭痛にて近医を受診. 脳底動脈先 端部に動脈瘤を指摘され紹介された，動脈瘤の大きさは $13 \mathrm{~mm}$, broad neckで, 右内頸動脈は閉塞していた。右 中大脳動脈領域への血流は前交通動脈と右後交通動脈より 認めたが，主に右後交通動脈より描出されていた。手術は 橈骨動脈を用いて右外頸動脈-中大脳動脈 (M2) バイパス (EC-RA-M2 bypass)を行ったのち, 右 anterior temporal approach にてクリッピングを行った(Fig. 1)。術後経過は 順調で神経症状を残すことなく退院し, 現在経過観察中で ある。

〈症例 2〉54歳男性. SAHにて発症。来院時 H\&K grade IV, 中等度右片麻痺があり, 脳底動脈先端部に動 脈瘤を認めた。動脈瘤の大きさは $25 \mathrm{~mm}$, 左内頸動脈は 閉塞し, 左後交通動脈を介して左中大脳動脈領域への血流 を認めるも, 左大脳半球の血流は対側と比べ低下していた $\left({ }^{99 \mathrm{~m}} \mathrm{Tc}-\mathrm{HMPAO}\right.$ 定性)。手術は，左 EC-RA-M2 bypass 行ったのち, 左 anterior temporal approachにてクリッピ ングを行った(Fig. 2)。術後経過は順調で神経症状を残す ことなく退院した．現在経過観察中である.

〈症例 3〉65歳女性. 頭痛にて来院. 左後大脳動脈 (P12)に動脈瘤を認め，左内頸動脈閉塞を伴っていた。動脈㢚 の大きさは $30 \mathrm{~mm}$, broad neck で, 脳底動脈先端部から 左後大脳動脈 $(\mathrm{P} 1)$ にかけての血管拡張も認め, 左後交通 動脈を介して左中大脳動脈が描出していた。手術は左 ECRA-M2 bypassを行ったのち, 左 anterior temporal approach にてクリッピングを行った（Fig. 3)。術後経過は 順調で神経症状を残すことなく退院し，その後外来で経過 をみていた。手術 10 年後より，もともと血管拡張がみら れていた脳底動脈先端部に動脈瘤が生じ，徐々に増大して いる (Fig. 4).

〈症例 4〉55歳女性．右動眼神経麻㾝にて来院．脳底動 脈・右上小脳動脈分岐部に大きさ $25 \mathrm{~mm}$ の動脈瘤を認め, 左内頸動脈閉塞を伴い，左後交通動脈を介する側副路が存 在した (Fig. 5). 左 EC-RA-M2 bypassを行い，2 日後右 anterior temporal approachにてクリッピングを行った. 動脈瘤より右上小脳動脈が直接分岐していたため，動脈㢚 

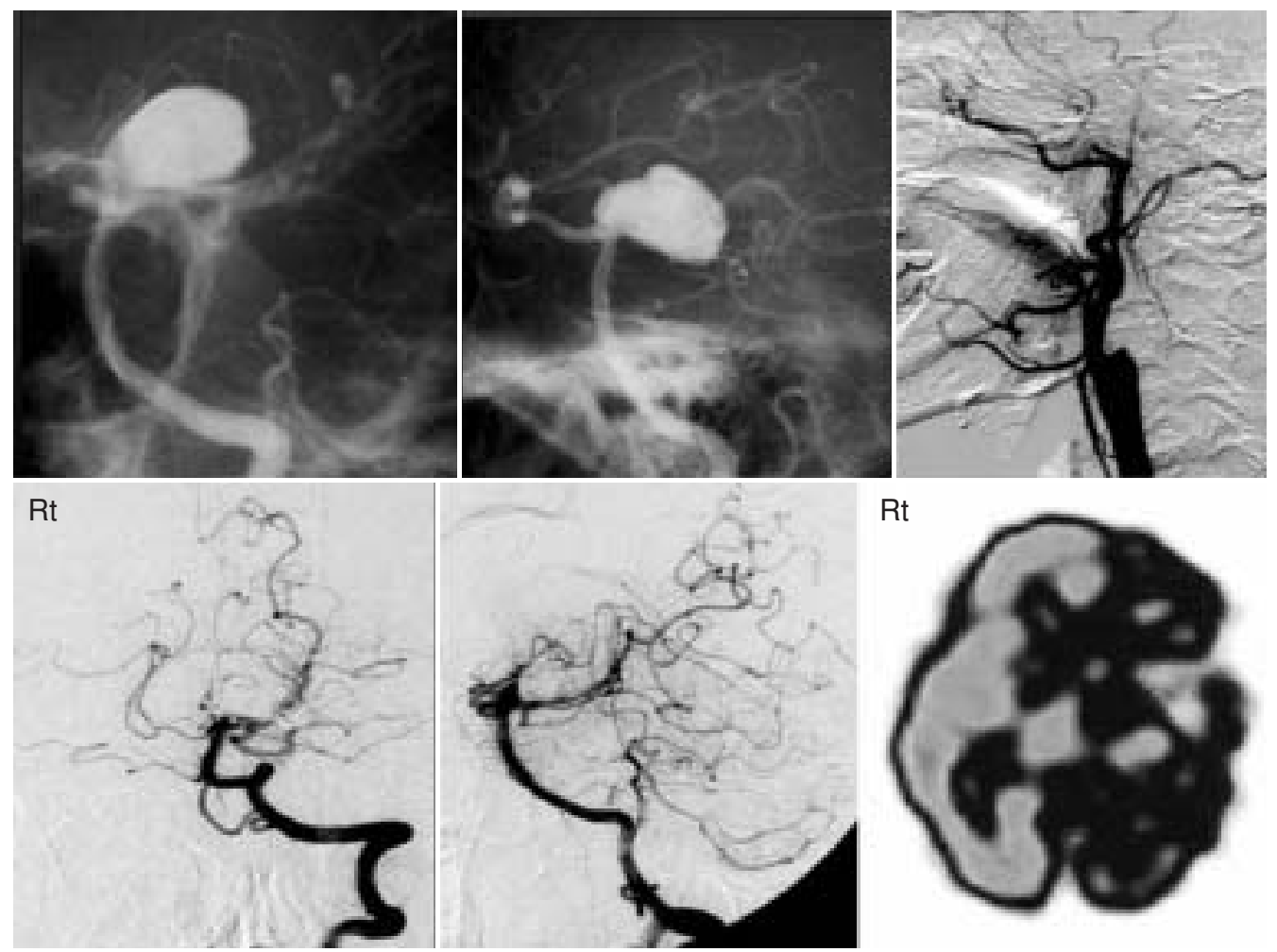

Fig. 2 Case 2. Angiograms show a basilar tip aneurysm: It. VAG before clipping; $L A O(A) \cdot$ lateral view (B), It. CAG lateral view (C), It. VAG after clipping; A-P view (D). lateral view (E). A SPECT $199 \mathrm{~m} T$ C-HMPAO qualitative analysis) reveals a decrease of It. cerebral blood flow $(\mathrm{F})$.

\begin{tabular}{l|l|l}
$A$ & $B$ & $C$ \\
\hline$D$ & $E$ & $F$
\end{tabular}

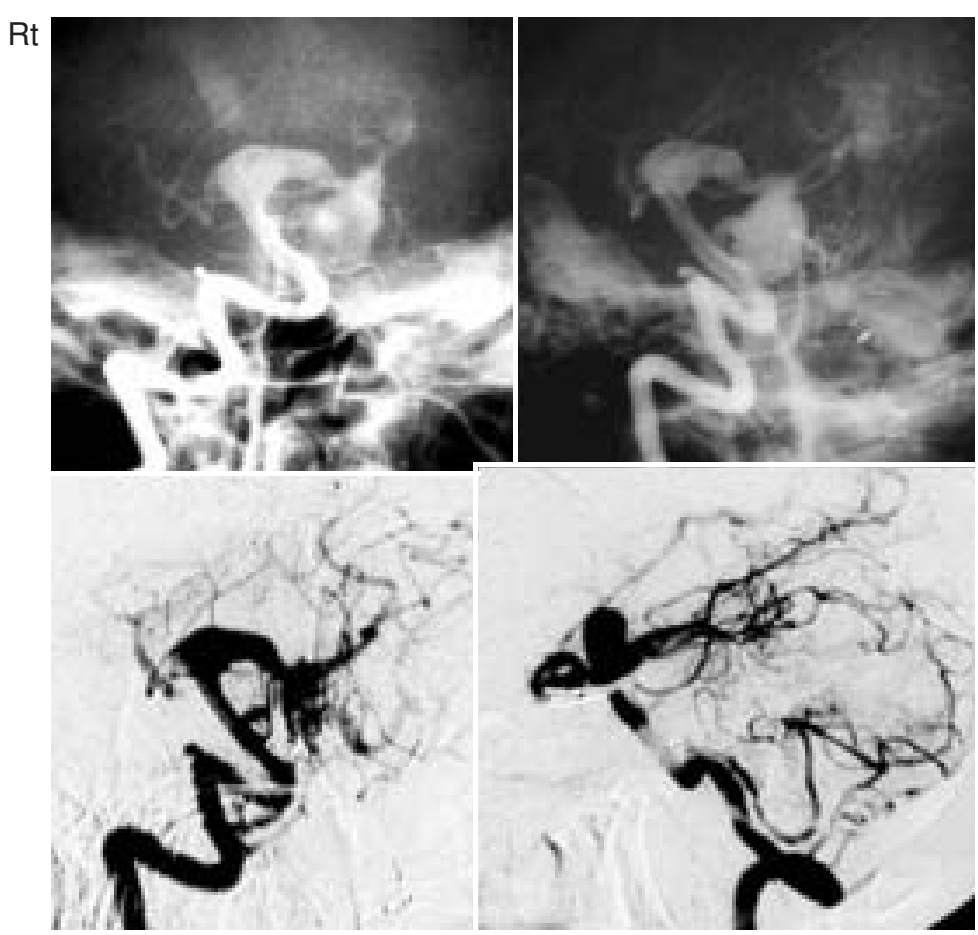

Fig. 3 Case 3. Angiograms (rt. VAG) show a It. P1-P2 aneurysm: before clipping (A; A-P view, B; lateral view), after clipping (C; A-P view, D; lateral view). 


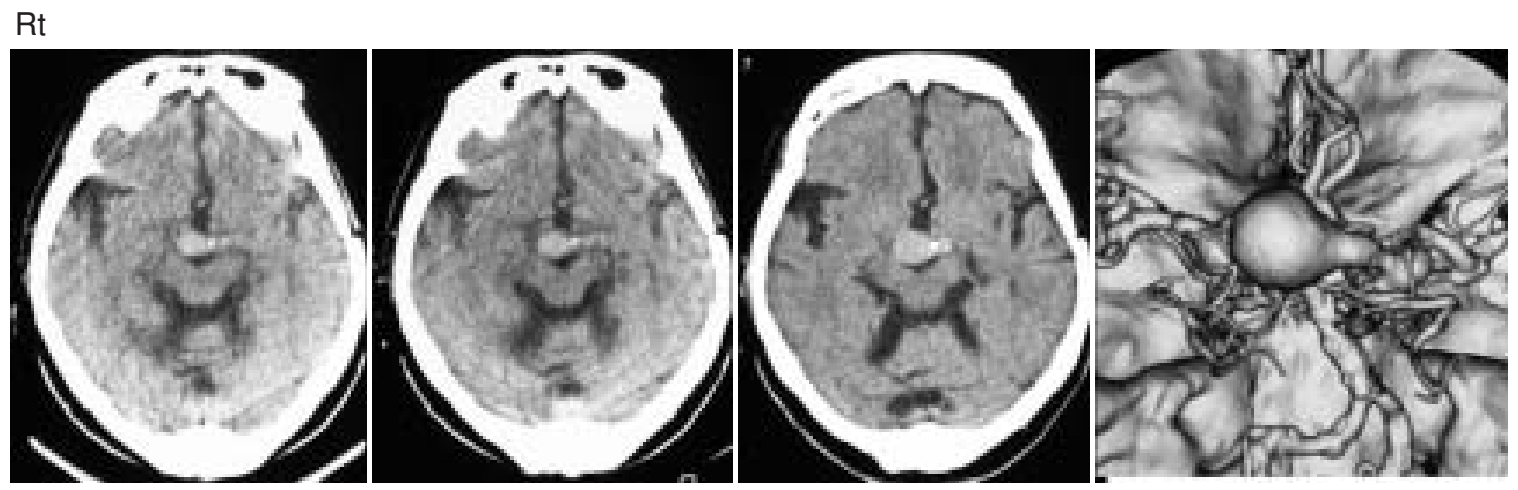

Fig. 4 Case 3. CTs and 3D-CTA reveal a basilar tip aneurysm which is growing; 7 years later $(A), 10$ years later $(B), 11$ years later $(C), 12$ years later (D) after operation.

$\mathrm{A}|\mathrm{B}| \mathrm{C} \mid \mathrm{D}$

Rt

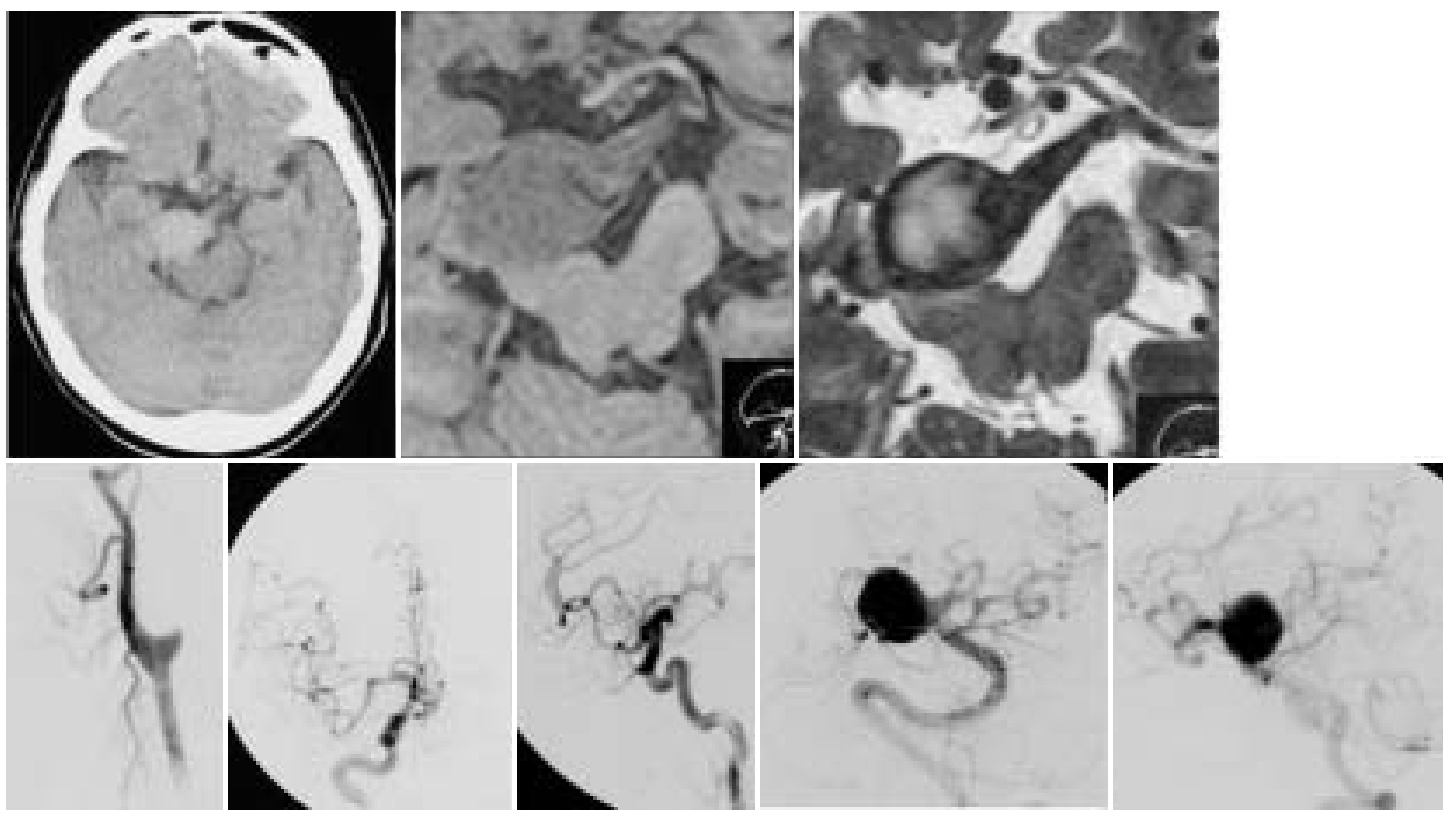

Fig. 5 Case 4. CT and MRI reveal rt. basilar-SCA aneurysm (A; CT, B; MRI T1 image, C; MRI T2 image). Angiograms show It. internal carotid artery occlusion (D; It. CAG lateral view, $E$; rt. CAG A-P view, F; rt. CAG lateral view, G; rt. VAG A-P view, $H$; rt. VAG lateral view).

は dome clippingに終わらざるをえなかった. 手術後麻 痺・失調などの症状を残すことなく経過していたが，動脈 瘤が徐々に増大し，側副路として存在していた左後交通動 脈の拡張もみられた(Fig. 6). 再手術を勧めたが同意が得 られず，手術 4 年後くも膜下出血を生じ死亡した。

\section{考察}

治療は全例において, hemodynamic stressを軽減し血 流を改善させる目的で内頸動脈閉塞側に EC-RA-M2 bypass 術を実施後，動脈瘤のクリッピングを行った。動 脈瘤のクリッピングに際しては，脳底動脈先端部およびそ の近傍が広く展開できる anterior temporal approachを全
例で用いて, 母動脈の確保は問題なく行えた.内頸動脈閉 塞側とアプローチサイドが異なる症例 4 は二期的に手術を 行ったが，その他の症例は一期的に手術を行った。 high flow bypassを行ったのちにクリッピングを行うと，手術 は煩雑となってしまい手術時間が長くなる. しかし，くも 膜下出血の場合，術後の脳虚血対策を考慮すると high flow bypassを含め一期的に手術を行ったほうがよいもの と考える. 手術が問題なく終わった症例 3 は術後 10 年を 経て動脈瘤が生じかつ増大し続け，不完全クリップに終わ った症例 4 は術後 4 年を経過したのち動脈瘤が増大して破 裂した。他の症例は経過観察期間が短いため，今後も注意 深く経過をみていく必要がある。 


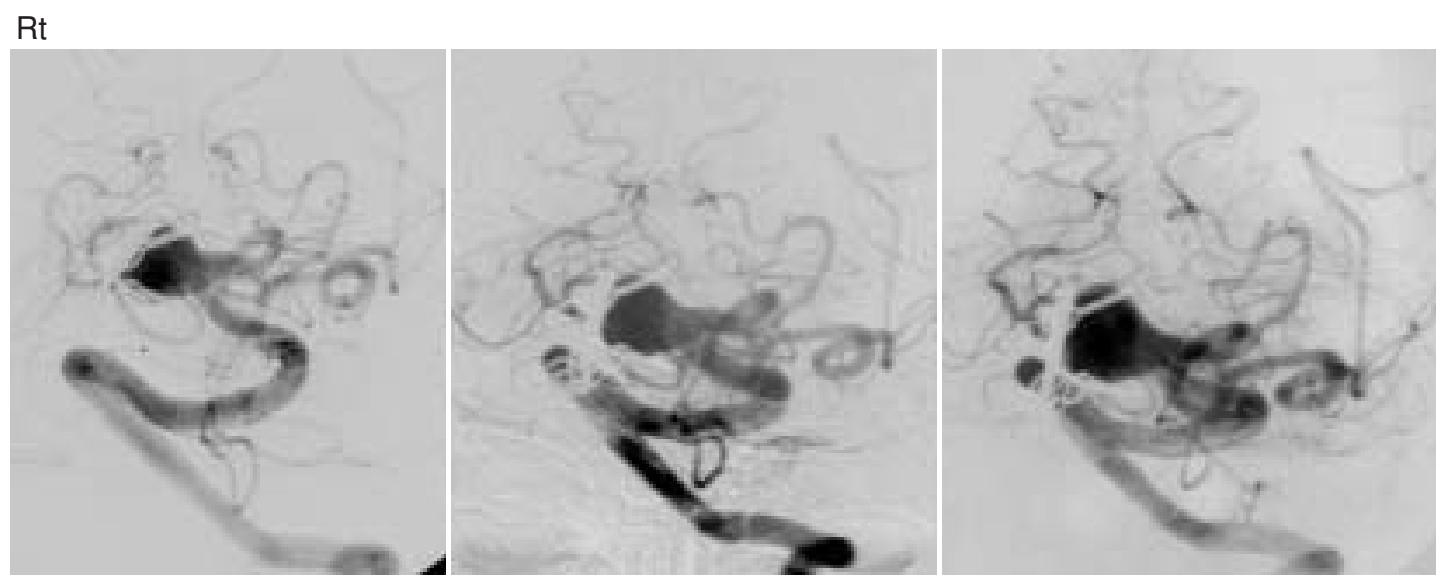

Fig. 6 Case 4. Angiograms (lt. VAG A-P view) show a residual rt. basilar-SCA aneurysm which is growing; just state (A), 2 years later (B), 4 years later $(C)$ after operation.

$\mathrm{A}|\mathrm{B}| \mathrm{C}$

海綿静脈洞部に生じた巨大動脈瘤やその他の内頸動脈瘤 に対し，治療目的で総頸動脈あるいは内頸動脈閉塞を行い 後日動脈瘤が生じた症例25)8)15), 内頸動脈形成不全に動 脈瘤を合併した症例 ${ }^{7)}$ などが報告されている。またテント 上動脈瘤において, 頭蓋外内頸動脈の狭窄あるいは閉塞を 有する率は約 $4 \%{ }^{13)}$ と報告されており, 動脈瘤が新たに発 生するまでの期間は 4-9 年 ${ }^{2)}$ 6) 8) 12) 15), 発生する動脈瘤の 部位は大部分が血行動態を反映して前交通動脈, 脳底動脈 先端部などの正中部あるいは閉塞部と反対側の内頸動脈で あった ${ }^{4)}$. 動脈瘤の大きさについて述べた報告はないが, 症例 1 でも動脈瘤の大きさが $10 \mathrm{~mm}$ を越え, 残りの症例 は巨大化し, 術野が深く母血管の確保が難しい脳底動脈先 端部およびその近傍に生じていた。島ら ${ }^{11)}$ の成犬を用い た実験では, 一側総頸動脈閉塞の場合, 脳底動脈の血流は 約 2.2 倍に, 雨側総頸動脈閉塞の場合約 4.1 倍に増加する と報告している，血管内治療が隆盛している現在，治療と

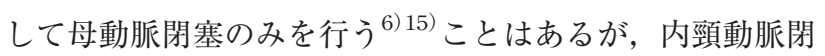
塞を伴うと, 今回のような治療が困難な場所に, 時に巨大 化した動脈瘤が生じる可能性があるため，母動脈閉塞のみ の治療は控えるべきと考える. STA-MCA bypassを動脈

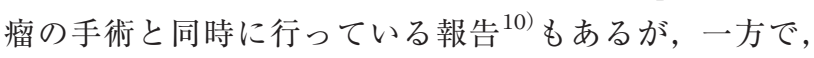
小児例でSTA-MCA bypassおよび内頸動脈閉塞を行って から 2 週間以内で, もともと存在していた脳底動脈瘤が破

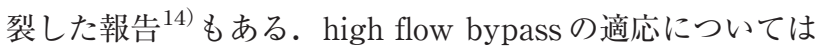
議論のあるところであるが, われわれは hemodynamic stress の軽減という観点から, クリッピングに先立ち high flow bypassを行うことがより適切ではないかと考えてい る. 動脈瘤の治療が完全に行えなかった症例 4 は最終的に くも膜下出血を生じ, すでに血管拡張を生じていた箇所に 新たに動脈瘤が生じた症例 3 は, high flow bypassを行っ ても動脈㾿の増大を防ぐことはできなかった，治療が完結
できなかった症例 4 においては, 初回手術で上小脳動脈を 温存するために動脈瘤の近位側ネックを大幅に残す形のク リッピングにしたため, 術後の動脈瘤増大は予見されてい た.したがって上小脳動脈への血行再建としてSTA-SCA バイパスを併用した血行再建を新たに追加し, 動脈瘤の完 全閉塞を行えば再破裂を予防できたと考える。しかし，症 例 3 に関しては, 動脈瘤発見時にすでに血管壁の異常があ り, 紡錘状動脈瘤として脳底動脈から左後大脳動脈にかけ て存在していた動脈瘤が顕在化したものと推察する。症例 3 の治療法としてクリッピングを考えたとき，年齢が 75 歳と高齢で母血管の動脈硬化が著しく, 動脈瘤 neck 周囲 の石灰化もあるためクリッピングは非常に困難と考える が, 動脈瘤がさらに大きくなると確実に破裂すると思われ る. 治療としては, 最初クリッピングを試みて, もし不可 能であれば敢えて partial clippingを行い動脈瘤頸部を狭 くしてから coil embolizationを行う方法 ${ }^{15)}$, 脳底動脈の hemodynamic stress を軽減させるために, 後大脳動脈領 域へのバイパスの追加などが考えられるが，治療にあたっ てはさらなる検討を要する.

通常われわれは，脳底動脈先端部近傍の動脈瘤をクリッ ピングするとき，母血管の一時遮断が短時間で済む場合 bypassは行わないが, 後大脳動脈や脳底動脈本幹を閉塞 しなければならない，あるいは長時間の一時遮断を要する ときには high flow bypassを行っている.また，上小脳動 脈の閉塞などが予想されるときには浅側頭動脈や後頭動脈 を用いてのbypassを行っている. bypassは, アプローチ 側と同じ側のときにはクリッピングに先立って行い，アプ ローチ側と異なるときには動脈瘤に対する血行動態の変化 を考慮し, bypassして数日以内にクリッピングを行った. 今回, 一側内頸動脈閉塞を伴っていたことから, hemodynamic stressの軽減およびspasm時の虚血への対応のた 
め high flow bypassを行った. しかし，動脈壁そのものが 変化, 脆弱化している場合には high flow bypassを行って も動脈瘤の増大を止められない場合があり, 治療の限界が あると思われた．high flow bypassを行ううえで最大の問 題点は graftの閉塞である。経験上，graft 閉塞の大部分は 手術中に生じるため, graftが patentであることを常に観 察しながら注意して手術を行わなければならない.

\section{結語}

内頸動脈閉塞を伴った巨大脳底動脈近傍動脈瘤を報告し た。橈骨動脈を用いて血行再建後クリッピングを行った。 術後当初は良好な成績を得たが，手術 4 年後に動脈瘤が再 増大してくも膜下出血を生じた症例，また術後 10 年を経 て動脈瘤が顕在化し増大した症例があることから，残りの 症例に関しても, 長期間の注意深い経過観察が必要と考え た。

\section{文献}

1) Batjer H, Mickey B, Samson D: Enlargement and rupture of distal of basilar artery aneurysm after iatrogenic carotid occlusion. Neurosurgery 20(4): 624-628, 1987

2) Fujiwara S, Fujii K, Fukui M: De novo aneurysm formation and aneurysm growth following therapeutic carotid occlusion for intracranial internal carotid artery (ICA) aneurysms. Acta Neurochir (Wien) 120: 20-25, 1993

3) Jaffe ME, McHenry LC Jr: Cerebral aneurysm following spontaneous carotid occlusion. Neurology 18: 1012-1014, 1968
4）片岡和夫，種子田護：両側頸動脈閉塞に合併した動脈瘤. Neurol Med Chir (Tokyo) 22: 744-750, 1982

5) Lubicz B, Gauvrit JY, Leclerc X, et al: Giant aneurysms of the internal carotid artery: endovascular treatment and long-term follow-up. Neuroradiology 45: 650-655, 2003

6) Maiuri F, Spaziante R, Iaconetta G, et al: 'De novo' aneurysm formation: report of two cases. Clin Neurol Neurosurg 97: 233-238, 1995

7) Osborn RE, Mojtahedi S, Hay TC, et al: Internal carotid artery hypoplasia. Comput Radiol 10: 283-287, 1986

8) Roski RA, Spetzler RF, Nulsen FE: Late complication of carotid ligation in the treatment of intracranial aneurysms. $J$ Neurosurg 54: 583-587, 1981

9）佐藤正夫，上山博康，中村俊孝，ほか：未破裂脳底動脈先 端部動脈瘤の手術 Coiling の可能性を残したPartial clipping: 抄録集 第 64 回日本脳神経外科学会総会，横浜，2005

10）佐山一郎，伊藤善太郎，中島健二，ほか：内頸動脈閉塞を 伴う多発脳動脈瘤の 2 例. 脳外 7: 797-804, 1979

11）島 健，石川 進，佐々木 潮，ほか：脳底動脈血流に関 する実験的研究. 脳神経外科 4(5)：451-457, 1976

12) Somach FM, Shenkin HA: Angiographic end-results of carotid ligation in the treatment of carotid aneurysm. $J$ Neurosurg 24: 966-974, 1966

13) Spallone A, Cantore G: The role of extracranial carotid abnormalities in the genesis of cerebral aneurysms. $J$ Neurosurg 55: 693-700, 1981

14）谷川緑野，上山博康，小林延光，ほか：Sylvian vein を温 存する anterior temporal approach の利点と欠点. The $M t$ Fuji Workshop on CVD vol 13，にゅーろん社，東京，1995, pp53-60

15) Wolf RL, Imbesi SG, Galetta SL, et al: Development of a posterior cerebral artery aneurysm subsequent to occlusion of the contralateral internal carotid artery for giant cavernous aneurysm. Neuroradiology 44: 443-446, 2002 